OPEN ACCESS

Edited by:

Xiaoyan Ding

Sun Yat-sen University, China

Reviewed by:

Ye Liu,

Zhejiang University, China

Wencui Wan

The First Affiliated Hospital of

Zhengzhou University, China

${ }^{*}$ Correspondence:

Yedi Zhou

zhouyedi@csu.edu.cn

Specialty section: This article was submitted to

Ophthalmology,

a section of the journal

Frontiers in Medicine

Received: 20 December 2021

Accepted: 12 January 2022

Published: 02 February 2022

Citation:

Tan W, Li B, Wang Z, Zou J, Jia Y, Yoshida S and Zhou Y (2022) Novel Potential Biomarkers for Retinopathy of Prematurity. Front. Med. 9:840030.

doi: $10.3389 /$ fmed.2022.840030

\section{Novel Potential Biomarkers for Retinopathy of Prematurity}

\author{
Wei Tan ${ }^{1,2}$, Bingyan $\mathrm{Li}^{1,2}$, Zicong Wang ${ }^{1,2}$, Jingling Zou ${ }^{1,2}$, Yang Jia ${ }^{3}$, Shigeo Yoshida ${ }^{4}$ and \\ Yedi Zhou ${ }^{1,2 *}$ \\ ${ }^{1}$ Department of Ophthalmology, The Second Xiangya Hospital of Central South University, Changsha, China, ${ }^{2}$ Hunan Clinical \\ Research Center of Ophthalmic Disease, Changsha, China, ${ }^{3}$ Department of Pediatrics, The Second Xiangya Hospital of \\ Central South University, Changsha, China, ${ }^{4}$ Department of Ophthalmology, Kurume University School of Medicine, Kurume, \\ Japan
}

Retinopathy of prematurity $(\mathrm{ROP})$ is the main risk factor for vision-threatening disease in premature infants with low birth weight. An accumulating number of independent studies have focused on ROP pathogenesis and have demonstrated that laser photocoagulation therapy and/or anti-VEGF treatment are effective. However, early diagnosis of ROP is still critical. At present, the main method of ROP screening is based on binocular indirect ophthalmoscopy. However, the judgment of whether ROP occurs and whether treatment is necessary depends largely on ophthalmologists with a great deal of experience. Therefore, it is essential to develop a simple, accurate and effective diagnostic method. This review describes recent findings on novel biomarkers for the prediction, diagnosis and prognosis of ROP patients. The novel biomarkers were separated into the following categories: metabolites, cytokines and growth factors, non-coding RNAs, iconography, gut microbiota, oxidative stress biomarkers, and others. Biomarkers with high sensitivity and specificity are urgently needed for the clinical applications of ROP. In addition, using non-invasive or minimally invasive methods to obtain samples is also important. Our review provides an overview of potential biomarkers of ROP.

Keywords: biomarker, retinopathy of prematurity, metabolites, cytokines and growth factors, non-coding RNAs, gut microbiota, oxidative stress biomarkers, iconography

\section{INTRODUCTION}

Retinopathy of prematurity (ROP) is a major cause of vision loss and blindness in children worldwide (1-3). As perinatal oxygen metabolism disorder causes hypoxia-ischemia, the compensatory secretion of pathological angiogenic factors and then the formation of retinal neovascularization contributes to abnormal retinal blood vessel development and even tractional retinal detachment (4-6). Preterm infants have immature retinal tissue, shorter axial lengths and thicker corneas and are more likely to suffer from $\operatorname{ROP}(7,8)$. Epidemiological studies have shown that the incidence of premature newborns is approximately $10 \%$, and infants with lower birth weight and gestational age have a higher incidence and severity of ROP. A total of $65.8 \%$ of preterm infants with a birth weight of $<1,251 \mathrm{~g}$ suffer from ROP to a certain degree; $81.6 \%$ of infants with a birth weight of $<1,000 \mathrm{~g}$ suffer from $\operatorname{ROP}(9,10)$. However, ROP is a largely preventable disease. Reducing the incidence of blindness is related to high-quality newborn care, a comprehensive ROP screening program, and experienced ROP ophthalmologists (11). Laser photocoagulation combined with intravitreal injection of anti-vascular endothelial growth factor (VEGF) drugs after early detection is effective (12-14). 
At present, ROP screening is based on birth weight and gestational age. Binocular indirect ophthalmoscopy (BIO) bedside examination, as well as wide-field fundus imaging system, are widely applied for ROP screening $(15,16)$. Recently, telemedicine and artificial intelligence-based ROP screening are considered to be more suitable in remote areas that are lack trained ophthalmologists (16-18). However, these screening methods have not been widely implemented, and the judgment of whether the therapeutic treatment is required for ROP infants mainly depends on the clinical experiences of the ophthalmologists (19-21). Furthermore, the molecular diagnostic methods and diagnostic criteria of ROP have not yet been clarified. A balance between the accurate identification of newborns with ROP that need therapy and a reduction in workload is required to save resources and avoid the unnecessary inspection of prematurity (22).

Biomarkers are indicators that are defined as objective measurements and evaluations that are used to evaluate normal biological processes, pathogenic processes, and responses to intervention or exposure (23). Biomarkers are mainly divided into seven categories, including diagnosis, monitoring, drug efficacy/response, prediction, prognosis, safety and susceptibility/risk biomarkers $(23,24)$. Blood is easy to obtain, and blood draw is a relatively non-invasive method (25). Some diseases have been distinguished using blood-based biomarkers, such as human epidermal growth factor receptor 2 (HER2) for breast cancer $(26,27)$ and epidermal growth factor receptor (EGFR) for lung cancer $(28,29)$. In addition to blood biomarkers, biomarkers from urine, feces and cerebrospinal fluid can be used to identify diseases. One such biomarker in the spinal fluid is myelin oligodendrocyte glycoprotein (MOG-IgG) and aquaporin-4 (AQP4), which are used to identify neuromyelitis optica spectrum disorders (30). In the field of ophthalmology, imaging findings and artificial intelligence analysis have been used as biomarkers for prediction and therapy response of choroidal diseases (31-33), and intraretinal cysts can be used for the prognosis of neovascular age-related macular (AMD) disease (34). Our review provides an overview of biomarkers in ROP and summarized in Figure 1.

\section{CANDIDATES OF NOVEL POTENTIAL BIOMARKERS}

\section{Metabolites}

ROP is related to hypoxia and nutrient deprivation in the maturation of retinal blood vessels, and regulation of retinal metabolism can prevent pathological angiogenesis. Recent research on the metabolic changes of ROP shows that metabolites can serve as biomarkers (35). Metabolomics affects cell physiology by regulating the genome, epigenome, transcriptome, and proteome (36). A study on targeted blood metabolomics in premature neonates showed that elevated levels of malonyl carnitine (C3DC) and glycine in the blood are promising biomarkers for prediction but cannot judge severity (37). Another plasma metabolomics study on treatmentrequiring $\mathrm{ROP}$ indicated that altered metabolites may be used as diagnostic and prognostic biomarkers, including the majority of altered amino acids and their derivatives (38). Further targeted metabolomics research found that plasma citrulline, arginine and aminoadipate were increased in patients with ROP, but creatine was reduced. They are all potential biomarkers (39). The oxygeninduced retinopathy (OIR) model is an animal model that has been widely used in the study of retinal neovascular diseases and is similar to the pathological process of ROP $(40,41)$. By analyzing the plasma from an OIR rat model, $\mathrm{Lu}$ et al. found that proline and "arginine and proline metabolism" pathways are potential biomarkers for the diagnosis of ROP (42). A prospective study by Nilsson et al. analyzed the changes in serum sphingolipidome in very preterm infants and concluded that a low concentration of sphingosine-1-phosphate signaling lipid is strongly related to severe ROP (43). Lower levels of the $\omega-6$ long-chain polyunsaturated fatty acid arachidonic acid (AA) are closely related to the development of ROP and is beneficial for the prediction of ROP (44). Table 1 summarizes these metabolism biomarkers.

\section{Cytokines and Growth Factors}

The immune-inflammatory environment before and after delivery of preterm infants may be a crucial factor leading to the progression of ROP (45). Various inflammatory cytokines and chemokines have been extensively investigated, and changes in their levels may be potential candidates for novel biomarkers of ROP. A study indicated that the increase in inflammatory factors (interleukin (IL)-6 and IL-8) and angiogenic mediators (endoglin, endostatin and insulin-like growth factor-binding protein (IGFBP)-2) in amniotic fluid is related to the occurrence and development of ROP. The use of these biomarkers in combination with prenatal factors can establish a prenatal prediction pattern of ROP (46). Another similar study suggested that an increase in IL-6 in umbilical cord plasma can predict ROP severity, and the elevated concentration of C5a can be used to assess whether laser treatment is required. Furthermore, the combined application is more accurate in the prediction of ROP development (45). In umbilical cord serum, elevated levels of IL-7, monocyte chemotactic protein-1 (MCP-1), macrophage inflammatory protein $1 \alpha(\mathrm{MIP}-1 \alpha)$ and MIP- $1 \beta$ contribute to predicting the risk of ROP, while MIP- $1 \beta$ is related to ROP severity (47). High levels of VEGF-Receptor 1, IL-8, matrix metalloproteinase 9 (MMP-9), erythropoietin (EPO), tumor necrosis factor (TNF)- $\alpha$ and basic fibroblast growth factor (bFGF) are related to a risk factor for prethreshold ROP in the first three postnatal weeks (48). A similar study showed that IL6 is significantly increased and IL-17 is decreased on Days 0-3 after birth. On Days 7-21, transforming growth factor- $\beta$ (TGF$\beta)$, brain-derived neurotrophic factor (BDNF), and regulated upon activation, normal $\mathrm{T}$ cell expressed and secreted (RANTES) were significantly reduced. IL-18, CRP and NT-4 concentrations were changed in both time periods (49). On Day 28, elevated concentrations of IL- 6 , TNF- $\alpha$, TNF-R1/-R2, and IL- 8 were related to the risk of ROP (48), and decreased serum levels of EPO was determined to be an independent factor for ROP prediction (50). In the tears of severe ROP, MMP-9 is elevated. Moreover, in the ROP vitreous, MMP9, complement factor $\mathrm{H}(\mathrm{CFH}), \mathrm{C} 3$, 


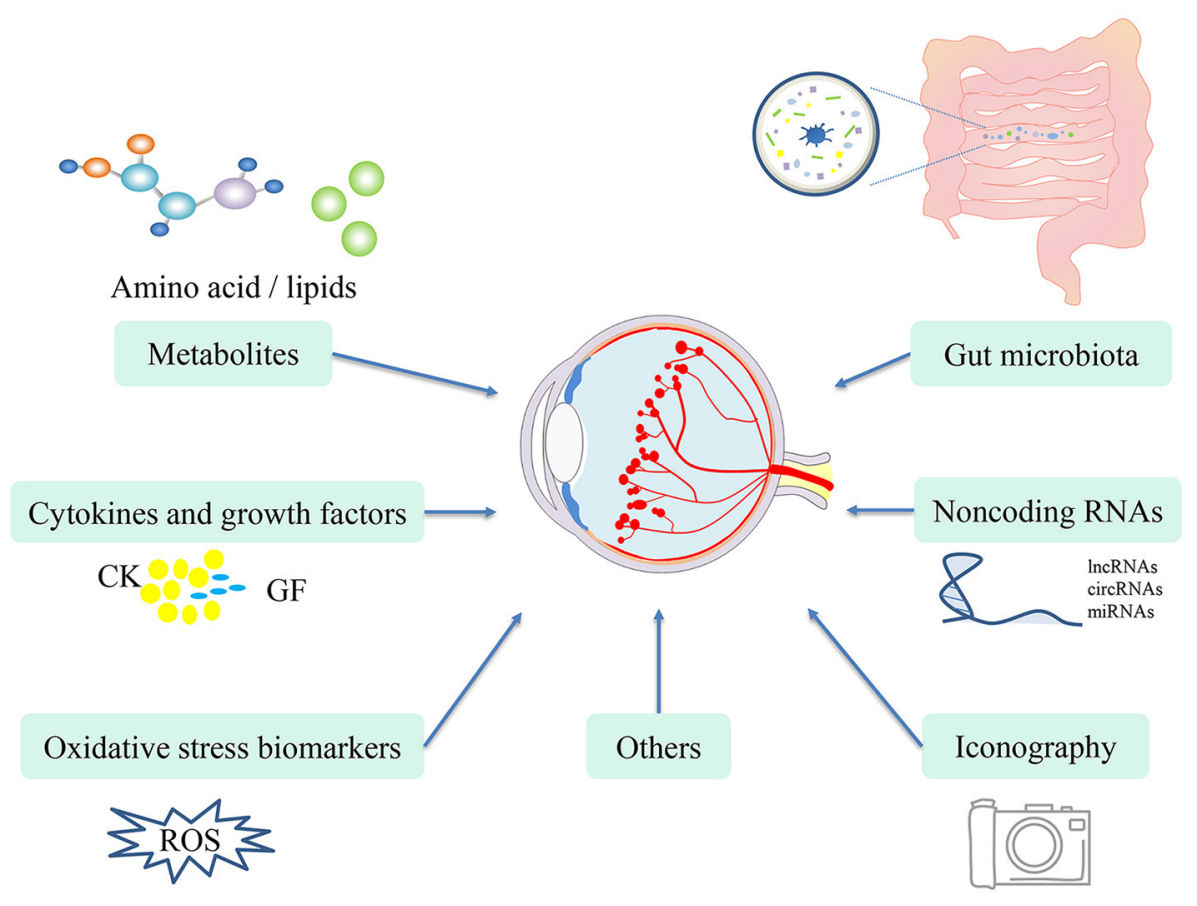

FIGURE 1 | Novel potential biomarkers for ROP, including metabolites, cytokines and growth factors, ncRNAs, iconography, gut microbiota, oxidative stress biomarkers and others.

TABLE 1 | Metabolites as potential biomarkers for ROP patients.

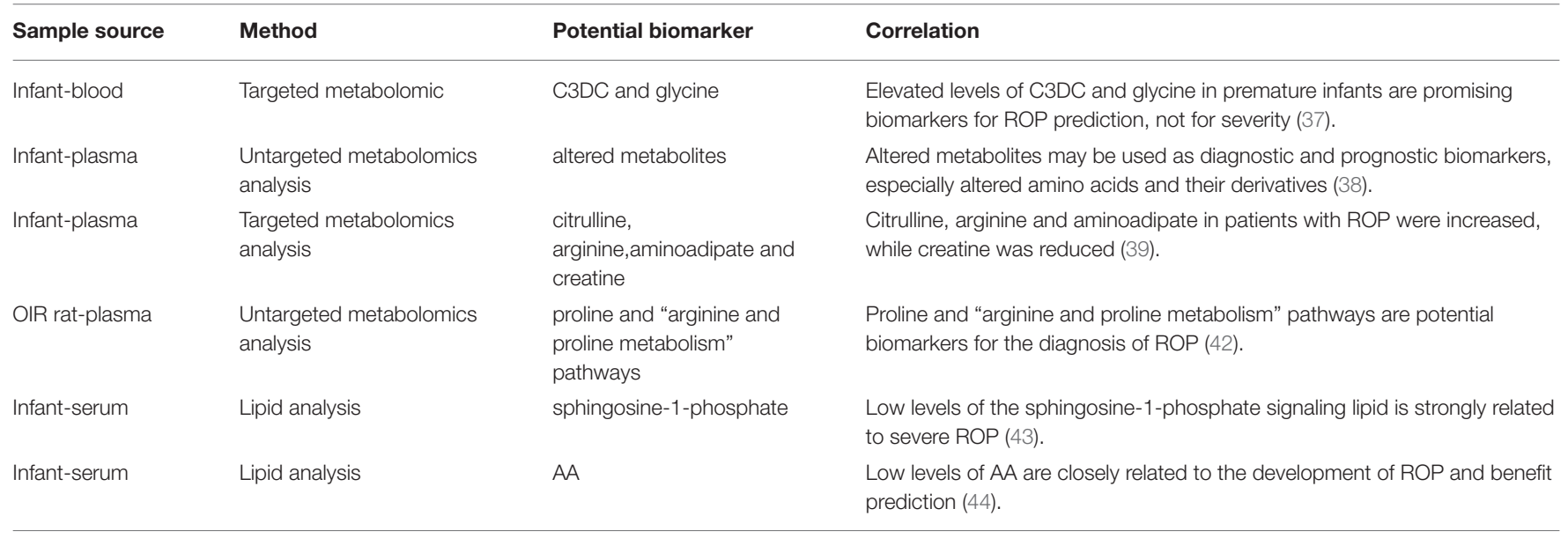

C4, IL-1ra, VEGF and granulocyte colony-stimulating factor (GCSF) are also increased (51). VEGF is elevated, and insulinlike growth factor 1 (IGF-1) is reduced in the cord blood of ROP patients. Serum IL-33 and endocan could be predictive biomarkers for severe ROP. These serum concentrations were higher and then significantly reduced after laser treatment (52). VEGF, interferon- $\gamma$ (IFN- $\gamma$ ), IL-10 and IL-12 are elevated in the aqueous humor of ROP patients, and higher levels of VEGF and MIP- $1 \beta$ are independently associated with ROP retreatment (53). At birth, infants with proliferative ROP have a low level of serum IL-5. Ten to 14 days after birth, babies without ROP have higher levels of serum BDNF and RANTES than infants with proliferative ROP (54). At $24 \mathrm{~h}$ after birth, the levels of proinflammatory cytokines (IL-6 and TNF- $\alpha$ ) were increased in children who received ROP therapeutic treatment. However, the concentration of IL- 6 was negatively correlated with IGF-1 in ROP infants of 5-8 weeks after birth (55).

IGF-1 is the primary factor involved in the growth of fetal tissues. Under normal circumstances, sufficient levels of serum IGF-1 are required for VEGF-stimulated retinal angiogenesis, but premature delivery causes a sudden decrease in serum IGF1 levels $(56,57)$. Clinical studies in the United States (56) and 
Europe (58) have shown that a low concentration of IGF-1 is related to the subsequent progression of severe ROP, so it is a risk predictor. The early return of IGF-1 to normal levels in premature infants can prevent ROP (59). The critical time for the detection of serum IGF-1 is in the third week after delivery (57). Visfatin is an adipocytokine that has a similar to insulin function and IGF-1 level, and it could be considered to be a predictor of ROP (60). Serum VEGF levels at birth are reduced in premature newborns who develop ROP later and may be an ROP predictor (61). VEGF and stromal cell-derived factor $1 \alpha$ (SDF$1 \alpha$ ) are elevated in the vitreous of stage 4 ROP (62). Among the proangiogenic factors in infant tears, angiogenin/VEGF can be used as a potential non-invasive screening biomarker for ROP (63). However, Woo et al. found that inflammatory cytokines (IL-1 $\beta$, IL-4, IL-6, IL-8, IL-10, IL12, IFN- $\gamma$, and TNF- $\alpha$ ) and growth factors (IGF-1 and VEGF) in cord blood samples may not predict ROP (64). Lymphocyte count is negatively correlated with ROP and may have an independent predictive value. However, the neutrophil-to-lymphocyte ratio (NLR) is not an independent predictor of ROP (65). Table 2 summarizes the cytokine and growth factor biomarkers.

\section{Non-coding RNA}

Non-coding RNAs (ncRNAs) are a type of RNA that does not encode proteins (66). However, they can still affect normal gene expression and participate in physiological and pathological processes through various mechanisms (67-69). Types of ncRNAs include long non-coding RNAs (lncRNAs), circular RNAs (circRNAs), and microRNAs (miRNAs), etc. (70). CircRNA is a single-stranded closed circular ncRNA. Compared to other RNAs, it has a longer half-life, better stability and increased resistance to RNase $\mathrm{R}$, making it a potential biomarker and therapeutic target (71-73). In fact, the expression and function of various circRNAs have been indicated in different cancers (74) and ocular diseases (75). Based on an OIR mouse model, Liu et al. found that the expression of cZNF609 in the retina was largely reduced during the vascular occlusion phase and significantly increased during the neovascularization phase. It combines with miR-615-5p as a miRNA sponge to regulate the gene expression of human umbilical vein endothelial cells (76). MiRNAs are small ncRNAs that can influence gene expression by influencing transcription, translation and epigenetics (77). At present, most studies on miRNAs and ROP are derived from research in animal models $(78,79)$. Metin et al. (80) performed the first clinical study. Through the analysis of 13 cases of ROP and 15 cases of premature infants without ROP, they found that miR-23a and miR-200b-3p were significantly elevated in premature infants with ROP, while miR-27b-3p and miR-214$3 p$ were reduced. These altered miRNAs could be considered as possible biomarkers of ROP (80). Furthermore, there are some related transcriptomics and bioinformatics analyses that can also provide novel for ncRNA as ROP biomarkers (81-83).

\section{Oxidative Stress Biomarkers}

ROP is a neonatal disease that is associated with oxidative stress. When a premature baby is born, it suddenly changes from a very low oxygen intrauterine environment to an artificial hyperoxia treatment environment. Due to an insufficient antioxidant protection capacity, it is in a state of oxidative stress, and the retina is particularly sensitive to oxidative stress $(84,85)$. The glutathione status of red blood cells is an indicator of oxidative stress in preterm infants, and it aids in the early identification of children at risk of ROP (86). The acrolein-lysine adduct was elevated in the premature infant group with active retinopathy compared with the preterm group without retinopathy (87).

The levels of 8-hydroxy 2-deoxyguanosine (8-OHdG) and malondialdehyde (MDA) are significantly higher in the blood and urine of ROP patients than in non-ROP patients. Based on this correlation, they could be used as screening indicators for ROP (88). In umbilical cord plasma, elevated levels of the oxidative stress biomarker MDA and reduced levels of the micronutrient vitamin $\mathrm{A}$ in infants are independent predictors of ROP (89). Other studies also recognized that total oxidative status (TOS) and MDA are satisfactory markers of oxidative stress, which is increased in the ROP group (90). Peroxidant antioxidant balance $(\mathrm{PAB})$ contributes to the incidence of ROP, and the severity of ROP increases with PAB (91).

\section{Gut Microbiome}

Although the human intestine is far from the eye, ophthalmological diseases are related to the regulation of systemic immunity. Emerging investigations into changes in the gut microbiota have been reported with a focus on uveitis $(92,93)$ and $\operatorname{AMD}(94,95)$, and the concept of the gut-retina axis has emerged $(94,96)$. The maternal gut microbiota plays a key role in the health of infants (97). We can screen out differentially expressed gut microbes and explore the potential biomarkers of ROP. Such biomarkers could have important clinical significance and application value for the preliminary screening of certain concealed and difficult-to-diagnose ROPs. Westaway et al. suggested that preterm birth-related diseases are associated with the gut microbiome and that $\alpha$-diversity in ROP infants was significantly reduced (98). Other studies proposed that Enterobacteriaceae species are enriched a few weeks before the diagnosis of ROP, while amino acid synthesis is more abundant in the non-ROP group $(99,100)$. Changes in the intestinal flora are promising targets for prevention and therapy in ROP patients. Such changes are closely related to metabolites. Therefore, it might be effective to utilize beneficial bacteria or produce antibodies against pathogenic bacteria to prevent or treat ROP in infants.

\section{Iconography}

In some remote regions, telemedicine technology with a digital fundus camera has been used for the screening and diagnosis of ROP (101). The swept-source optical coherence tomography imaging is used to determine the choroidal vascularity index (CVI), which is more sensitive than subfoveal choroidal thickness in assessing related choroidal structural changes in premature infants with a history of ROP. A decrease in CVI indicates impaired choroidal vascular function (102). 
TABLE 2 | Cytokines and growth factors as potential biomarkers for ROP patients.

\begin{tabular}{|c|c|c|c|}
\hline Sample source & Method & Potential biomarker & Correlation \\
\hline $\begin{array}{l}\text { Infant-amniotic } \\
\text { fluid }\end{array}$ & ELISA & $\begin{array}{l}\text { IL-6, IL-8, endoglin, } \\
\text { endostatin and IGFBP-2 }\end{array}$ & $\begin{array}{l}\text { Inflammatory factors (IL-6 and IL-8) and angiogenic mediators (endoglin, } \\
\text { endostatin and IGFBP-2) in amniotic fluid are related to the occurrence and } \\
\text { development of ROP (46). }\end{array}$ \\
\hline Infant-plasma & ELISA & IL-6 and C5a & $\begin{array}{l}\text { High IL-6 levels predict ROP severity, while elevated concentrations of C5a } \\
\text { assess whether laser treatment is required. The combined application is } \\
\text { more accurate in predicting ROP development (45). }\end{array}$ \\
\hline Infant-serum & multiplex protein arrays & $\begin{array}{l}\mathrm{IL}-7, \mathrm{MCP}-1, \mathrm{MIP}-1 \alpha \text { and } \\
\mathrm{MIP}-1 \beta\end{array}$ & $\begin{array}{l}\text { Elevated levels of IL-7, MCP- } 1, \text { MIP- } 1 \alpha \text { and MIP- }-1 \beta \text { contribute to prediction } \\
\text { of the risk of ROP, and MIP- } 1 \beta \text { is related to ROP severity (47). }\end{array}$ \\
\hline Infant-blood & $\begin{array}{l}\text { meso scale discovery } \\
\text { multiplex platform and } \\
\text { microplate detection } \\
\text { platform }\end{array}$ & $\begin{array}{l}\text { VEGF-R1, IL-8, MMP-9, } \\
\text { EPO, TNF- } \alpha \text { and bFGF }\end{array}$ & $\begin{array}{l}\text { High levels of VEGF-R1, IL-8, MMP-9, EPO, TNF- } \alpha \text { and bFGF are related to } \\
\text { a risk factor for prethreshold ROP in the first three postnatal weeks. On Day } \\
28 \text {, elevated concentrations of IL-6, TNF- } \alpha, \mathrm{TNF}-\mathrm{R} 1 /-\mathrm{R} 2, \mathrm{IL}-8 \text { are still } \\
\text { related to the risk (48). }\end{array}$ \\
\hline Infant-blood & Multiplex Luminex assay & $\begin{array}{l}\text { IL-6, IL-17, TGF- } \beta, \text { BDNF, } \\
\text { RANTES, IL-18, CRP and } \\
\text { NT-4 }\end{array}$ & $\begin{array}{l}\text { IL-6 is significantly increased and IL-17 is decreased on Days 0-3 after } \\
\text { birth. On Days } 7-21 \text {, TGF- } \beta \text {, BDNF, and RANTES are significantly reduced. } \\
\text { IL-18, CRP and NT-4 were changed in both time periods (49). }\end{array}$ \\
\hline Infant-serum & ELISA & EPO & $\begin{array}{l}\text { On Day 28, decreased serum levels of EPO were determined to be } \\
\text { independent factors for ROP prediction (50). }\end{array}$ \\
\hline $\begin{array}{l}\text { Infant-vitreous and } \\
\text { tear }\end{array}$ & multiplex bead arrays & $\begin{array}{l}\text { MMP9, CFH, C3, C4, } \\
\text { IL-1ra, VEGF and G-CSF }\end{array}$ & $\begin{array}{l}\text { In tears of severe ROP, MMP-9 is elevated. In the ROP vitreous, MMP9, } \\
\text { CFH, C3, C4, IL-1ra, VEGF and G-CSF are also increased (51). }\end{array}$ \\
\hline Infant-blood & ELISA & $\begin{array}{l}\text { VEGF, IGF-1, IL-33 and } \\
\text { endocan }\end{array}$ & $\begin{array}{l}\text { VEGF is elevated and IGF-1 is reduced in cord blood of ROP patients. } \\
\text { Serum IL-33 and endocan could be predictive biomarkers for severe } \\
\text { ROP (52). }\end{array}$ \\
\hline $\begin{array}{l}\text { Infant-aqueous } \\
\text { humor }\end{array}$ & multiplex bead assay & $\begin{array}{l}\text { VEGF, IFN- } \gamma, \mathrm{IL}-10, \mathrm{IL}-12 \\
\text { and MIP-1 } \beta\end{array}$ & $\begin{array}{l}\text { VEGF, IFN- } \gamma \text {, IL-10 and IL-12 in ROP patients are elevated, and higher } \\
\text { levels of VEGF and MIP-1 } \beta \text { are independently associated with ROP } \\
\text { retreatment (53). }\end{array}$ \\
\hline Infant-serum & multiplex immunoassay & IL-5, BDNF and RANTES & $\begin{array}{l}\text { Infants at birth with proliferative ROP have a low level of serum IL-5. Ten to } \\
14 \text { days after birth, babies without ROP have higher levels of serum BDNF } \\
\text { and RANTES than infants with proliferative ROP (54). }\end{array}$ \\
\hline Infant-blood & $\begin{array}{l}\text { human Luminex XMAP } \\
\text { assay }\end{array}$ & IL-6, TNF- $\alpha$ and IGF-1 & $\begin{array}{l}\text { At } 24 \mathrm{~h} \text { after birth, the levels of IL- } 6 \text { and TNF- } \alpha \text { are both increased in } \\
\text { children who received ROP treatment, while the concentration of IL-6 is } \\
\text { negatively correlated with IGF- } 1 \text { between } 5-8 \text { weeks after birth (55). }\end{array}$ \\
\hline Infant-serum & $\begin{array}{l}\text { ELISA and IGF binding } \\
\text { protein-blocked } \\
\text { radioimmunoassay }\end{array}$ & IGF-1 & $\begin{array}{l}\text { A low concentration of IGF- } 1 \text { is related to the subsequent progression of } \\
\text { severe ROP, so it is a risk predictor }(56,58) \text {. In addition, the early return of } \\
\text { IGF- } 1 \text { to normal levels in premature infants can prevent ROP (59). The critical } \\
\text { time for the detection of serum IGF- } 1 \text { is in the third week after delivery (57). }\end{array}$ \\
\hline Infant-blood & Enzyme immunoassay & IGF-1 and Visfatin & $\begin{array}{l}\text { Visfatin is an adipocytokine that has a similar to insulin function and IGF-1 } \\
\text { level, and could be considered a predictor of ROP (60). }\end{array}$ \\
\hline Infant-blood & ELISA & VEGF & $\begin{array}{l}\text { Serum VEGF levels are reduced in premature newborns who develop ROP, } \\
\text { and may be a predictor of ROP (61). }\end{array}$ \\
\hline Infant-vitreous & ELISA & VEGF and SDF- $1 \alpha$ & VEGF and SDF- $1 \alpha$ are elevated in the vitreous of stage 4 ROP (62). \\
\hline Infant-tear fluid & multiplex ELISA & Angiogenin and VEGF & $\begin{array}{l}\text { Among the pro-angiogenic factors in the tears of infants, angiogenin/VEGF } \\
\text { may be a potential non-invasive screening biomarker for ROP (63). }\end{array}$ \\
\hline Infant-blood & $\begin{array}{l}\text { ABX Pentra DF120/USA } \\
\text { biochemical analyzer }\end{array}$ & Lymphocyte count & $\begin{array}{l}\text { Lymphocyte count is negatively correlated with ROP and may be an } \\
\text { independent predictor (65). }\end{array}$ \\
\hline
\end{tabular}

\section{Other Biomarkers}

There is significant thrombocytopenia in the blood samples of infants with treatment-requiring ROP, and this could be a predictor of disease progression (103). Platelet mass index is a reliable monitoring indicator for the prognosis of ROP in very premature newborns (104). The percentage of fetal hemoglobin after birth is negatively correlated with the severity of ROP (105). The complete blood count, including low concentrations of hemoglobin, can be a simple screening indicator for ROP; this is especially true for the mean corpuscular hemoglobin (106). Mutations in a Wnt signaling receptor protein (FZD4) gene may be an indicator of ROP (107). High levels of neonatal hemoglobin A1C are a feasible biomarker for proliferative ROP, and low levels of $\mathrm{A} 1 \mathrm{C}$ are a feasible biomarker for non-proliferative ROP (108). Elevated plasma E-selection levels and recombinant human erythropoietin (rhEPO) are independent risk predictors for the progression of ROP (109-111). The serine protease HTRA-1 is the basis of protection against preeclampsia-mediated ROP and prevents the occurrence of diseases (112). An increase in the concentration of lactate and a low value for the perfusion index may be early parameters that can be used to predict ROP (113). The lack of human chorionic gonadotropin (hCG) at 4 
weeks after birth may be related to non-proliferative ROP (114). The increase in urinary $\mathrm{N}$-terminal B-type natriuretic peptide (NT-proBNP) in the early stage of preterm infants ( $<30$ weeks of gestational age) and the NT-proBNP/creatinine ratio can identify the risk of severe ROP $(115,116)$. However, the changes in NTproBNP disappear in more mature infants (117). Cluster analysis showed that an early increase in the levels of Parkinson disease protein 7 (PARK7), vimentin, myeloperoxidase (MPO), CD69, and NF- $\kappa \mathrm{B}$ essential modulator (NEMO) in plasma is related to a decrease in ROP risk. However, lower levels of tumor necrosis factor receptor superfamily member 4 (TNFRSF4) and higher levels of HER2 and galanin could predict the progression of ROP (118). In addition, a meta-analysis suggested that polymorphisms in the angiotensin-converting enzyme (ACE) I/D may be a genetic biomarker of an increased risk of ROP (119). The mean blur rate (MBR) was higher in OIR rats than in the control group, and it was significantly correlated with avascular area/total retinal area (\%AVA) and retinal VEGF, therefore, MBR could be used to assess the severity of OIR (120).

\section{COMPARISON OF DIFFERENT DETECTION METHODS}

Although various biomarkers are associated with ROP, whether their different detection methods are easy and fast is an important part of determining the feasibility of their final application in premature infants. Premature infants are fragile, and thus, it is highly important to avoid invasive operations, such as obtaining aqueous humor. Less invasive examinations, such as blood tests, are reliable sources of biomarkers, and most of the potential biomarkers we summarized above are also obtained from blood. In addition to collecting plasma or serum, peripheral blood mononuclear cells (PBMCs) could be obtained during the blood examination. PBMCs are an essential part of the immune system. They are related to inflammatory cells and can release a large number of paracrine factors (121-124). They are potentially an important source of biomarkers that are related to cytokines and growth factors. In addition, saliva has been used to determine the level of melatonin in premature infants. No significant difference in the level of melatonin between serum and saliva has been demonstrated, and a high degree of correlation was observed (125). Perhaps these findings can provide new ideas for exploring biomarkers. It is convenient to collect urine. Urine is rich in metabolites and can reflect the total imbalance of all biochemical pathways in the body (126). It is worth further exploring the value of such non-invasive, pain-free and easy-to-obtain samples as potential monitoring, diagnostic and prognostic biomarkers in ROP.

\section{REFERENCES}

1. Kim SJ, Port AD, Swan R, Campbell JP, Chan RVP, Chiang MF. Retinopathy of prematurity: a review of risk factors and their clinical significance. Surv Ophthalmol. (2018) 63:618-37. doi: 10.1016/j.survophthal.2018.04.002

2. Solebo AL, Teoh L, Rahi J. Epidemiology of blindness in children. Arch Dis Child. (2017) 102:853-7. doi: 10.1136/archdischild-2016-310532

\section{CONCLUSION}

All over the world, the incidence of ROP is increasing in countries that have the technology to save premature infants $(127,128)$. If patients can be diagnosed in a timely manner, an effective treatment could restore vision. However, regrettably, the diagnosis of ROP depends on pediatric ophthalmologists with a great deal of clinical experience, and this diagnosis has a high degree of subjectivity and variability (129). It is easy to ignore abnormal conditions of the eyes because infants are unable to speak, but it could eventually lead to irreversible vision loss in some cases. Therefore, it is believed that the discovery of effective ROP biomarkers is very important. Reliable and easily available biomarkers will provide considerable information on diseases and aid in the development of new effective therapies (130). With the development of emerging laboratory medical technologies, microfluidic chips (131), proteomics (132) and single-cell technologies (133), also contribute to the exploration of biomarkers, which also deserve to be further revealed in ROP studies. In this review, we summarized several strong potential biomarkers including metabolites, cytokines and growth factors, ncRNAs, gut microbiota, iconography, oxidative stress biomarkers, etc. Since newborns are fragile, these markers should preferably be found in non-invasive and easily accessible samples, such as blood, urine and feces. Those studies and methods might contribute to the identification of effective biomarkers that shed light to the prediction and treatment of ROP.

\section{AUTHOR CONTRIBUTIONS}

YZ contributed to the conceptualization, design, and outline of this review. WT prepared the draft of the manuscript with tables and figures. BL, ZW, and JZ contributed to the literature search. YJ and SY contributed to the revision and editing. All authors have read and approved the final manuscript.

\section{FUNDING}

This work was supported by Changsha Science and Technology Project (kq1907075) and the Fundamental Research Funds for the Central Universities of Central South University (No. 2021zzts1056).

\section{ACKNOWLEDGMENTS}

The authors would like to thank Prof. Yun Li for important advice regarding the manuscript.

3. Good WV. Retinopathy of prematurity incidence in children. Ophthalmology. (2020) 127:S82-3. doi: 10.1016/j.ophtha.2019.11.026

4. GBD 2019 Blindness and Vision Impairment Collaborators, Vision Loss Expert Group of the Global Burden of Disease Study. Causes of blindness and vision impairment in 2020 and trends over 30 years, and prevalence of avoidable blindness in relation to VISION 2020: the Right to Sight: an analysis for the Global Burden of Disease Study. 
Lancet Glob Health. (2021) 9:e144-60. doi: 10.1016/S2214-109X(20)3 0489-7

5. Hellström A, Smith LE, Dammann O. Retinopathy of prematurity. Lancet. (2013) 382:1445-57. doi: 10.1016/S0140-6736(13)60178-6

6. Patel CK, Carreras E, Henderson RH, Wong SC, Berg S. Evolving outcomes of surgery for retinal detachment in retinopathy of prematurity: the need for a national service in the United Kingdom: an audit of surgery for acute tractional retinal detachment complicating ROP in the UK. Eye. (2021). doi: 10.1038/s41433-021-01679-8. [Epub ahead of print].

7. Fierson WM. Screening examination of premature infants for retinopathy of prematurity. Pediatrics. (2018) 142:e20183061. doi: 10.1542/peds.2018-3061

8. Kardaras D, Papageorgiou E, Gaitana K, Grivea I, Dimitriou VA, Androudi $\mathrm{S}$, et al. The association between retinopathy of prematurity and ocular growth. Invest Ophthalmol Vis Sci. (2019) 60:98-106. doi: 10.1167/iovs.1824776

9. Palmer EA, Flynn JT, Hardy RJ, Phelps DL, Phillips CL, Schaffer DB, et al. Incidence and early course of retinopathy of prematurity. Ophthalmology. (2020) 127:S84-96. doi: 10.1016/j.ophtha.2020.01.034

10. Goldenberg RL, Culhane JF, Iams JD, Romero R. Epidemiology and causes of preterm birth. Lancet. (2008) 371:7584. doi: 10.1016/S0140-6736(08)60074-4

11. Adams GGW. ROP in Asia. Eye. (2020) 34:6078. doi: 10.1038/s41433-019-0620-y

12. Daruich A, Bremond-Gignac D, Behar-Cohen F, Kermorvant E. [Retinopathy of prematurity: from prevention to treatment]. Med Sci. (2020) 36:900-7. doi: 10.1051/medsci/2020163

13. Laveti V, Balakrishnan D, Rani PK, Mohamed A, Jalali S. Prospective clinical study of two different treatment regimens of combined laser photocoagulation and intravitreal bevacizumab for retinopathy of prematurity: the Indian Twin Cities ROP study (ITCROPS) database report number 9. Int Ophthalmol. (2020) 40:3539-45. doi: 10.1007/s10792-020-01543-w

14. Sen P, Wu WC, Chandra P, Vinekar A, Manchegowda PT, Bhende P. Retinopathy of prematurity treatment: Asian perspectives. Eye. (2020) 34:632-42. doi: 10.1038/s41433-019-0643-4

15. Wu C, Petersen RA, VanderVeen DK. RetCam imaging for retinopathy of prematurity screening. J AAPOS. (2006) 10:107-11. doi: 10.1016/j.jaapos.2005.11.019

16. Yonekawa Y, Thomas BJ, Thanos A, Todorich B, Drenser KA, Trese MT, et al. The cutting edge of retinopathy of prematurity care: expanding the boundaries of diagnosis and treatment. Retina. (2017) 37:220825. doi: 10.1097/IAE.0000000000001719

17. Scruggs BA, Chan RVP, Kalpathy-Cramer J, Chiang MF, Campbell JP. Artificial intelligence in retinopathy of prematurity diagnosis. Transl Vis Sci Technol. (2020) 9:5. doi: 10.1167/tvst.9.2.5

18. Patel TP, Aaberg MT, Paulus YM, Lieu P, Dedania VS, Qian CX, et al. Smartphone-based fundus photography for screening of plus-disease retinopathy of prematurity. Graefes Arch Clin Exp Ophthalmol. (2019) 257:2579-85. doi: 10.1007/s00417-019-04470-4

19. Chawla D, Deorari A. Retinopathy of prematurity prevention, screening and treatment programmes: progress in India. Semin Perinatol. (2019) 43:3447. doi: $10.1053 /$ j.semperi.2019.05.006

20. Yu TY, Donovan T, Armfield N, Gole GA. Retinopathy of prematurity: the high cost of screening regional and remote infants. Clin Exp Ophthalmol. (2018) 46:645-51. doi: 10.1111/ceo.13160

21. Quinn GE, Vinekar A. The role of retinal photography and telemedicine in ROP screening. Semin Perinatol. (2019) 43:367-74. doi: 10.1053/j.semperi.2019.05.010

22. Mgharbil E, Raffa LH, Alessa S, Alamri A. Screening premature infants for retinopathy of prematurity in a tertiary hospital in Saudi Arabia. Ann Saudi Med. (2020) 40:87-93. doi: 10.5144/0256-4947.2020.87

23. Califf RM. Biomarker definitions and their applications. Exp Biol Med. (2018) 243:213-21. doi: $10.1177 / 1535370217750088$

24. Pitkänen A, Ekolle Ndode-Ekane X, Lapinlampi N, Puhakka N. Epilepsy biomarkers - toward etiology and pathology specificity. Neurobiol Dis. (2019) 123:42-58. doi: 10.1016/j.nbd.2018.05.007

25. Best MG, Wesseling P, Wurdinger T. Tumor-educated platelets as a noninvasive biomarker source for cancer detection and progression monitoring. Cancer Res. (2018) 78:340712. doi: 10.1158/0008-5472.CAN-18-0887

26. Dieci MV, Miglietta F, Griguolo G, Guarneri V. Biomarkers for HER2positive metastatic breast cancer: beyond hormone receptors. Cancer Treat Rev. (2020) 88:102064. doi: 10.1016/j.ctrv.2020.102064

27. Loibl S, Gianni L. HER2-positive breast cancer. Lancet. (2017) 389:241529. doi: 10.1016/S0140-6736(16)32417-5

28. Sigismund S, Avanzato D, Lanzetti L. Emerging functions of the EGFR in cancer. Mol Oncol. (2018) 12:3-20. doi: 10.1002/1878-0261.12155

29. Hastings K, Yu HA, Wei W, Sanchez-Vega F, DeVeaux M, Choi J, et al. EGFR mutation subtypes and response to immune checkpoint blockade treatment in non-small-cell lung cancer. Ann Oncol. (2019) 30:131120. doi: $10.1093 /$ annonc/mdz141

30. Thoman ME, McKarns SC. Metabolomic profiling in neuromyelitis optica spectrum disorder biomarker discovery. Metabolites. (2020) 10:374. doi: 10.3390/metabo10090374

31. Schmidt-Erfurth U, Waldstein SM, Klimscha S, Sadeghipour A, Hu X, Gerendas BS, et al. Prediction of individual disease conversion in early amd using artificial intelligence. Invest Ophthalmol Vis Sci. (2018) 59:3199208. doi: $10.1167 /$ iovs.18-24106

32. Waldstein SM, Vogl WD, Bogunovic H, Sadeghipour A, Riedl S, SchmidtErfurth U. Characterization of drusen and hyperreflective foci as biomarkers for disease progression in age-related macular degeneration using artificial intelligence in optical coherence tomography. JAMA Ophthalmol. (2020) 138:740-7. doi: 10.1001/jamaophthalmol.2020.1376

33. Pichi F, Aggarwal K, Neri P, Salvetti P, Lembo A, Nucci P, et al. Choroidal biomarkers. Indian J Ophthalmol. (2018) 66:1716-26. doi: 10.4103/ijo.IJO_893_18

34. Ritter M, Simader C, Bolz M, Deák GG, Mayr-Sponer U, Sayegh R, et al. Intraretinal cysts are the most relevant prognostic biomarker in neovascular age-related macular degeneration independent of the therapeutic strategy. $\mathrm{Br}$ J Ophthalmol. (2014) 98:1629-35. doi: 10.1136/bjophthalmol-2014-305186

35. Tomita Y, Usui-Ouchi A, Nilsson AK, Yang J, Ko M, Hellström A, et al. Metabolism in retinopathy of prematurity. Life. (2021) 11:1119. doi: 10.3390/life11111119

36. Rinschen MM, Ivanisevic J, Giera M, Siuzdak G. Identification of bioactive metabolites using activity metabolomics. Nat Rev Mol Cell Biol. (2019) 20:353-67. doi: 10.1038/s41580-019-0108-4

37. Yang Y, Wu Z, Li S, Yang M, Xiao X, Lian C, et al. targeted blood metabolomic study on retinopathy of prematurity. Invest Ophthalmol Vis Sci. (2020) 61:12. doi: $10.1167 /$ iovs.61.2.12

38. Zhou Y, Xu Y, Zhang X, Zhao P, Gong X, He M, et al. Plasma metabolites in treatment-requiring retinopathy of prematurity: potential biomarkers identified by metabolomics. Exp Eye Res. (2020) 199:108198. doi: 10.1016/j.exer.2020.108198

39. Zhou Y, Xu Y, Zhang X, Huang Q, Tan W, Yang Y, et al. Plasma levels of amino acids and derivatives in retinopathy of prematurity. Int J Med Sci. (2021) 18:3581-7. doi: 10.7150/ijms.63603

40. Connor KM, Krah NM, Dennison RJ, Aderman CM, Chen J, Guerin KI, et al. Quantification of oxygen-induced retinopathy in the mouse: a model of vessel loss, vessel regrowth and pathological angiogenesis. Nat Protoc. (2009) 4:1565-73. doi: 10.1038/nprot.2009.187

41. Vähätupa $M$, Järvinen TAH, Uusitalo-Järvinen $H$. Exploration of oxygen-induced retinopathy model to discover new therapeutic drug targets in retinopathies. Front Pharmacol. (2020) 11:873. doi: 10.3389/fphar.2020.00873

42. Lu F, Liu Y, Guo Y, Gao Y, Piao Y, Tan S, et al. Metabolomic changes of blood plasma associated with two phases of rat OIR. Exp Eye Res. (2020) 190:107855. doi: 10.1016/j.exer.2019.107855

43. Nilsson AK, Andersson MX, Sjöbom U, Hellgren G, Lundgren P, Pivodic A, et al. Sphingolipidomics of serum in extremely preterm infants: association between low sphingosine-1-phosphate levels and severe retinopathy of prematurity. Biochim Biophys Acta Mol Cell Biol Lipids. (2021) 1866:158939. doi: 10.1016/j.bbalip.2021.158939

44. Löfqvist CA, Najm S, Hellgren G, Engström E, Sävman K, Nilsson AK, et al. Association of retinopathy of prematurity with low levels of arachidonic acid: a secondary analysis of a randomized clinical trial. JAMA Ophthalmol. (2018) 136:271-7. doi: 10.1001/jamaophthalmol.2017.6658 
45. Park YJ, Woo SJ, Kim YM, Hong S, Lee YE, Park KH. Immune and inflammatory proteins in cord blood as predictive biomarkers of retinopathy of prematurity in preterm infants. Invest Ophthalmol Vis Sci. (2019) 60:381320. doi: 10.1167 /iovs. $19-27258$

46. Woo SJ, Park JY, Hong S, Kim YM, Park YH, Lee YE, et al. Inflammatory and angiogenic mediators in amniotic fluid are associated with the development of retinopathy of prematurity in preterm infants. Invest Ophthalmol Vis Sci. (2020) 61:42. doi: 10.1167/iovs.61.5.42

47. Yu H, Yuan L, Zou Y, Peng L, Wang Y, Li T, et al. Serum concentrations of cytokines in infants with retinopathy of prematurity. Apmis. (2014) 122:818-23. doi: 10.1111/apm.12223

48. Holm M, Morken TS, Fichorova RN, VanderVeen DK, Allred EN, Dammann $\mathrm{O}$, et al. Systemic inflammation-associated proteins and retinopathy of prematurity in infants born before the 28th week of gestation. Invest Ophthalmol Vis Sci. (2017) 58:6419-28. doi: 10.1167/iovs.17-21931

49. Sood BG, Madan A, Saha S, Schendel D, Thorsen P, Skogstrand $\mathrm{K}$, et al. Perinatal systemic inflammatory response syndrome and retinopathy of prematurity. Pediatr Res. (2010) 67:394400. doi: 10.1203/PDR.0b013e3181d01a36

50. Yang X, Ze B, Dai Y, Zhu L, Chen C. The alteration and significance of erythropoietin serum levels in preterm infants with retinopathy of prematurity. Am J Perinatol. (2017) 34:1020-5. doi: 10.1055/s-0037-1601486

51. Rathi S, Jalali S, Patnaik S, Shahulhameed S, Musada GR, Balakrishnan $\mathrm{D}$, et al. Abnormal complement activation and inflammation in the pathogenesis of retinopathy of prematurity. Front Immunol. (2017) 8:1868. doi: 10.3389/fimmu.2017.01868

52. Cakir U, Tayman C, Yucel C, Ozdemir O. Can IL-33 and endocan be new markers for retinopathy of prematurity? Comb Chem High Throughput Screen. (2019) 22:41-8. doi: 10.2174/1386207322666190325120244

53. Lyu J, Zhang Q, Jin $\mathrm{H}, \mathrm{Xu} \mathrm{Y,} \mathrm{Chen} \mathrm{C,} \mathrm{Ji} \mathrm{X,} \mathrm{et} \mathrm{al.} \mathrm{Aqueous} \mathrm{cytokine}$ levels associated with severity of type 1 retinopathy of prematurity and treatment response to ranibizumab. Graefes Arch Clin Exp Ophthalmol. (2018) 256:1469-77. doi: 10.1007/s00417-018-4034-5

54. Hellgren G, Willett K, Engstrom E, Thorsen P, Hougaard DM, Jacobsson B, et al. Proliferative retinopathy is associated with impaired increase in BDNF and RANTES expression levels after preterm birth. Neonatology. (2010) 98:409-18. doi: 10.1159/000317779

55. Hellgren G, Löfqvist C, Hansen-Pupp I, Gram M, Smith LE, Ley D, et al. Increased postnatal concentrations of pro-inflammatory cytokines are associated with reduced IGF-I levels and retinopathy of prematurity. Growth Horm IGF Res. (2018) 39:19-24. doi: 10.1016/j.ghir.2017.11.006

56. Jensen AK, Ying GS, Huang J, Quinn GE, Binenbaum G. Postnatal serum insulin-like growth factor I and retinopathy of. prematurity. Retina. (2017) 37:867-72. doi: 10.1097/IAE.0000000000001247

57. Pérez-Muñuzuri A, Fernández-Lorenzo JR, Couce-Pico ML, BlancoTeijeiro MJ, Fraga-Bermúdez JM. Serum levels of IGF1 are a useful predictor of retinopathy of prematurity. Acta Paediatr. (2010) 99:51925. doi: 10.1111/j.1651-2227.2009.01677.x

58. Hellström A, Engström E, Hård AL, Albertsson-Wikland K, Carlsson B, Niklasson A, et al. Postnatal serum insulin-like growth factor I deficiency is associated with retinopathy of prematurity and other complications of premature birth. Pediatrics. (2003) 112:1016-20. doi: 10.1542/peds.112.5.1016

59. Hellstrom A, Perruzzi C, Ju M, Engstrom E, Hard AL, Liu JL, et al. Low IGF-I suppresses VEGF-survival signaling in retinal endothelial cells: direct correlation with clinical retinopathy of prematurity. Proc Natl Acad Sci U S A. (2001) 98:5804-8. doi: 10.1073/pnas.101113998

60. Cekmez F, Canpolat FE, Çetinkaya M, Pirgon O, Aydinoz S, Ceylan OM, et al. IGF-I and visfatin levels in retinopathy of prematurity. J Pediatr Ophthalmol Strabismus. (2012) 49:120-4. doi: 10.3928/01913913-20110531-01

61. Yenice O, Cerman E, Ashour A, Firat R, Haklar G, Sirikci O, et al. Serum erythropoietin, insulin-like growth factor 1, and vascular endothelial growth factor in etiopathogenesis of retinopathy of prematurity. Ophthalmic Surg Lasers Imaging Retina. (2013) 44:549-54. doi: 10.3928/23258160-20131105-05

62. Sonmez K, Drenser KA, Capone A, Trese MT. Vitreous levels of stromal cell-derived factor 1 and vascular endothelial growth factor in patients with retinopathy of prematurity. Ophthalmology. (2008) 115:106570. doi: 10.1016/j.ophtha.2007.08.050

63. Vinekar A, Nair AP, Sinha S, Vaidya T, Chakrabarty K, Shetty R, et al. Tear fluid angiogenic factors: potential noninvasive biomarkers for retinopathy of prematurity screening in preterm infants. Invest Ophthalmol Vis Sci. (2021) 62:2. doi: 10.1167/iovs.62.3.2

64. Woo SJ, Park KH, Lee SY, Ahn SJ, Ahn J, Park KH, et al. The relationship between cord blood cytokine levels and perinatal factors and retinopathy of prematurity: a gestational age-matched case-control study. Invest Ophthalmol Vis Sci. (2013) 54:3434-9. doi: 10.1167/iovs.13-11837

65. Kurtul BE, Kabatas EU, Zenciroglu A, Ozer PA, Ertugrul GT, Beken S, et al. Serum neutrophil-to-lymphocyte ratio in retinopathy of prematurity. J AAPOS. (2015) 19:327-31. doi: 10.1016/j.jaapos.2015.04.008

66. Liu Y, Liu X, Lin C, Jia X, Zhu H, Song J, et al. Non-coding RNAs regulate alternative splicing in cancer. J Exp Clin Cancer Res. (2021) 40:11. doi: 10.1186/s13046-020-01798-2

67. Mattick JS, Makunin IV. Non-coding RNA. Hum Mol Genet. (2006) 15:R1729. doi: $10.1093 / \mathrm{hmg} / \mathrm{ddl} 046$

68. Matsui M, Corey DR. Non-coding RNAs as drug targets. Nat Rev Drug Discov. (2017) 16:167-79. doi: 10.1038/nrd.2016.117

69. Panni S, Lovering RC, Porras P, Orchard S. Non-coding RNA regulatory networks. Biochim Biophys Acta Gene Regul Mech. (2020) 1863:194417. doi: 10.1016/j.bbagrm.2019.194417

70. Filardi T, Catanzaro G, Mardente S, Zicari A, Santangelo C, Lenzi A, et al. Non-coding RNA: role in gestational diabetes pathophysiology and complications. Int J Mol Sci. (2020) 21:4020. doi: 10.3390/ijms21114020

71. Jeck WR, Sharpless NE. Detecting and characterizing circular RNAs. Nat Biotechnol. (2014) 32:453-61. doi: 10.1038/nbt.2890

72. Memczak S, Jens M, Elefsinioti A, Torti F, Krueger J, Rybak A, et al. Circular RNAs are a large class of animal RNAs with regulatory potency. Nature. (2013) 495:333-8. doi: 10.1038/nature11928

73. Zhou WY, Cai ZR, Liu J, Wang DS, Ju HQ, Xu RH. Circular RNA: metabolism, functions and interactions with proteins. Mol Cancer. (2020) 19:172. doi: 10.1186/s12943-020-01286-3

74. Lei B, Tian Z, Fan W, Ni B. Circular RNA: a novel biomarker and therapeutic target for human cancers. Int J Med Sci. (2019) 16:292301. doi: 10.7150/ijms.28047

75. Zhang $\mathrm{C}, \mathrm{Hu} \mathrm{J}, \mathrm{Yu} \mathrm{Y}$. CircRNA is a rising star in researches of ocular diseases. Front Cell Dev Biol. (2020) 8:850. doi: 10.3389/fcell.2020.00850

76. Liu C, Yao MD, Li CP, Shan K, Yang H, Wang JJ, et al. Silencing of circular RNA-ZNF609 ameliorates vascular endothelial dysfunction. Theranostics. (2017) 7:2863-77. doi: 10.7150/thno.19353

77. Chen L, Heikkinen L, Wang C, Yang Y, Sun H, Wong G. Trends in the development of miRNA bioinformatics tools. Brief Bioinform. (2019) 20:1836-52. doi: 10.1093/bib/bby054

78. Chen XK, Ouyang LJ, Yin ZQ, Xia YY, Chen XR, Shi H, et al. Effects of microRNA-29a on retinopathy of prematurity by targeting AGT in a mouse model. Am J Transl Res. (2017) 9:791-801.

79. Fan YY, Liu CH, Wu AL, Chen HC, Hsueh YJ, Chen KJ, et al. MicroRNA-126 inhibits pathological retinal neovascularization via suppressing vascular endothelial growth factor expression in a rat model of retinopathy of prematurity. Eur J Pharmacol. (2021) 900:174035. doi: 10.1016/j.ejphar.2021.174035

80. Metin T, Dinç E, Görür A, Erdogan S, Ertekin S, Sari AA, et al. Evaluation of the plasma microRNA levels in stage 3 premature retinopathy with plus disease: preliminary study. Eye. (2018) 32:415-20. doi: 10.1038/eye.20 17.193

81. Zhao R, Qian L, Jiang L. Identification of retinopathy of prematurity related miRNAs in hyperoxia-induced neonatal rats by deep sequencing. Int J Mol Sci. (2014) 16:840-56. doi: 10.3390/ijms16010840

82. Cao M, Zhang L, Wang JH, Zeng H, Peng Y, Zou J, et al. Identifying circRNAassociated-ceRNA networks in retinal neovascularization in mice. Int J Med Sci. (2019) 16:1356-65. doi: 10.7150/ijms.35149

83. Peng Y, Zou J, Wang JH, Zeng H, Tan W, Yoshida S, et al. Small RNA sequencing reveals transfer RNA-derived small RNA expression profiles in retinal neovascularization. Int J Med Sci. (2020) 17:171322. doi: 10.7150/ijms.46209 
84. Graziosi A, Perrotta M, Russo D, Gasparroni G, D’Egidio C, Marinelli B, et al. Oxidative stress markers and the retinopathy of prematurity. J Clin Med. (2020) 9:2711. doi: 10.3390/jcm9092711

85. Stone WL, Shah D, Hollinger SM. Retinopathy of prematurity: an oxidative stress neonatal disease. Front Biosci. (2016) 21:165-77. doi: 10.2741/4382

86. Oziebło-Kupczyk M, Bakunowicz-Lazarczyk A, Dzienis K, Skrzydlewska E, Szczepański M, Waszkiewiczz E. [The estimation of selected parameters in antioxidant system in red blood cells in ROP screening of premature infants]. Klin Oczna. (2006) 108:413-5.

87. Tsukahara H, Jiang MZ, Ohta N, Sato S, Tamura S, Hiraoka M, et al. Oxidative stress in neonates: evaluation using specific biomarkers. Life Sci. (2004) 75:933-8. doi: 10.1016/j.lfs.2004.01.025

88. Ates O, Alp HH, Caner I, Yildirim A, Tastekin A, Kocer I, et al. Oxidative DNA damage in retinopathy of prematurity. Eur J Ophthalmol. (2009) 19:80-5. doi: 10.1177/112067210901900112

89. Agrawal G, Dutta S, Prasad R, Dogra MR. Fetal oxidative stress, micronutrient deficiency and risk of retinopathy of prematurity: a nested case-control study. Eur J Pediatr. (2021) 180:1487-96. doi: 10.1007/s00431-020-03896-x

90. Banjac L, Banjac G, Kotur-Stevuljević J, Spasojević-Kalimanovska $\mathrm{V}$, Gojković T, Bogavac-Stanojević N, et al. Pro-oxidants and antioxidants in retinopathy of prematurity. Acta Clin Croat. (2018) 57:458-63. doi: 10.20471/acc.2018.57.03.08

91. Boskabadi H, Marefat M, Maamouri G, Abrishami M, Abrishami M, Shoeibi $\mathrm{N}$, et al. Evaluation of pro-oxidant antioxidant balance in retinopathy of prematurity. Eye. (2021) 36:148-52. doi: 10.1038/s41433-021-01465-6

92. Jayasudha R, Kalyana Chakravarthy S, Sai Prashanthi G, Sharma S, Tyagi M, Shivaji S. Implicating dysbiosis of the gut fungal microbiome in uveitis, an inflammatory disease of the eye. Invest Ophthalmol Vis Sci. (2019) 60:138493. doi: 10.1167/iovs.18-26426

93. Horai R, Caspi RR. Microbiome and autoimmune uveitis. Front Immunol. (2019) 10:232. doi: 10.3389/fimmu.2019.00232

94. Rowan S, Jiang S, Korem T, Szymanski J, Chang ML, Szelog J, et al. Involvement of a gut-retina axis in protection against dietary glycemiainduced age-related macular degeneration. Proc Natl Acad Sci U S A. (2017) 114:E4472-e81. doi: 10.1073/pnas.1702302114

95. Rowan S, Taylor A. Gut microbiota modify risk for dietary glycemiainduced age-related macular degeneration. Gut Microbes. (2018) 9:4527. doi: 10.1080/19490976.2018.1435247

96. Rinninella E, Mele MC, Merendino N, Cintoni M, Anselmi G, Caporossi A, et al. The role of diet, micronutrients and the gut microbiota in age-related macular degeneration: new perspectives from the gut?retina axis. Nutrients. (2018) 10:1677. doi: 10.3390/nu10111677

97. Nyangahu DD, Jaspan HB. Influence of maternal microbiota during pregnancy on infant immunity. Clin Exp Immunol. (2019) 198:4756. doi: 10.1111/cei.13331

98. Westaway JAF, Huerlimann R, Kandasamy Y, Miller CM, Norton R, Staunton KM, et al. The bacterial gut microbiome of probiotic-treated very-preterm infants: changes from admission to discharge. Pediatr Res. (2021). doi: 10.1038/s41390-021-01888-7. [Epub ahead of print].

99. Mammas IN, Spandidos DA. Retinopathy of prematurity and neonatal gut microbiome: an interview with professor dimitra skondra, associate professor of ophthalmology and vitreoretinal surgeon at the university of chicago (USA). Exp Ther Med. (2020) 20:294. doi: 10.3892/etm.2020.9424

100. Skondra D, Rodriguez SH, Sharma A, Gilbert J, Andrews B, Claud EC. The early gut microbiome could protect against severe retinopathy of prematurity. J aapos. (2020) 24:236-8. doi: 10.1016/j.jaapos.2020.03.010

101. Chan-Ling T, Gole GA, Quinn GE, Adamson SJ, Darlow BA. Pathophysiology, screening and treatment of ROP: a multi-disciplinary perspective. Prog Retin Eye Res. (2018) 62:77-119. doi: 10.1016/j.preteyeres.2017.09.002

102. Lavric A, Tekavcic Pompe M, Markelj S, Ding J, Mahajan S, Khandelwal N, et al. Choroidal structural changes in preterm children with and without retinopathy of prematurity. Acta Ophthalmol. (2019). doi: 10.1111/aos.14324

103. Parrozzani R, Nacci EB, Bini S, Marchione G, Salvadori S, Nardo D, et al. Severe retinopathy of prematurity is associated with early post-natal low platelet count. Sci Rep. (2021) 11:891. doi: 10.1038/s41598-020-79535-0
104. Korkmaz L, Baştug O, Özdemir A, Korkut S, Karaca Ç, Akin MA, et al. Platelet mass index can be a reliable marker in predicting the prognosis of retinopathy of prematurity in very preterm infants. Pediatr Neonatol. (2018) 59:455-63. doi: 10.1016/j.pedneo.2017.11.001

105. Stutchfield CJ, Jain A, Odd D, Williams C, Markham R. Foetal haemoglobin, blood transfusion, and retinopathy of prematurity in very preterm infants: a pilot prospective cohort study. Eye. (2017) 31:14515. doi: 10.1038/eye.2017.76

106. Akyüz Ünsal A, Key Ö, Güler D, Kurt Omurlu I, Anik A, Demirci B, et al. Can complete blood count parameters predict retinopathy of prematurity? Turk J Ophthalmol. (2020) 50:87-93. doi: 10.4274/tjo.galenos.2019.45313

107. Dailey WA, Gryc W, Garg PG, Drenser KA. Frizzled-4 variations associated with retinopathy and intrauterine growth retardation: a potential marker for prematurity and retinopathy. Ophthalmology. (2015) 122:191723. doi: 10.1016/j.ophtha.2015.05.036

108. Movsas TZ, Muthusamy A. Feasibility of neonatal haemoglobin A1C as a biomarker for retinopathy of prematurity. Biomarkers. (2020) 25:46873. doi: 10.1080/1354750X.2020.1783573

109. Pieh C, Krüger M, Lagrèze WA, Gimpel C, Buschbeck C, Zirrgiebel U, et al. Plasma sE-selectin in premature infants: a possible surrogate marker of retinopathy of prematurity. Invest Ophthalmol Vis Sci. (2010) 51:370913. doi: $10.1167 /$ iovs.09-4723

110. Suk KK, Dunbar JA, Liu A, Daher NS, Leng CK, Leng JK, et al. Human recombinant erythropoietin and the incidence of retinopathy of prematurity: a multiple regression model. J AAPOS. (2008) 12:2338. doi: 10.1016/j.jaapos.2007.08.009

111. Manzoni P, Memo L, Mostert M, Gallo E, Guardione R, Maestri A, et al. Use of erythropoietin is associated with threshold retinopathy of prematurity (ROP) in preterm ELBW neonates: a retrospective, cohort study from two large tertiary NICUs in Italy. Early Hum Dev. (2014) 90:S2933. doi: 10.1016/S0378-3782(14)50009-6

112. Owen LA, Shirer K, Collazo SA, Szczotka K, Baker S, Wood B, et al. The serine protease HTRA-1 is a biomarker for ROP and mediates retinal neovascularization. Front Mol Neurosci. (2020) 13:605918. doi: 10.3389/fnmol.2020.605918

113. Tuten A, Dincer E, Topcuoglu S, Sancak S, Akar S, Hakyemez Toptan H, et al. Serum lactate levels and perfusion index: are these prognostic factors on mortality and morbidity in very low-birth weight infants? J Matern Fetal Neonatal Med. (2017) 30:1092-5. doi: 10.1080/14767058.2016.1205019

114. Movsas TZ, Paneth N, Gewolb IH, Lu Q, Cavey G, Muthusamy A. The postnatal presence of human chorionic gonadotropin in preterm infants and its potential inverse association with retinopathy of prematurity. Pediatr Res. (2020) 87:558-63. doi: 10.1038/s41390-019-0580-8

115. Czernik C, Metze B, Müller C, Müller B, Bührer C. Urinary N-terminal B-type natriuretic peptide predicts severe retinopathy of prematurity. Pediatrics. (2011) 128:e545-9. doi: 10.1542/peds.2011-0603

116. Bührer C, Erdeve Ö, van Kaam A, Berger A, Lechner E, Bar-Oz B, et al. Nterminal B-type natriuretic peptide urinary concentrations and retinopathy of prematurity. Pediatr Res. (2017) 82:958-63. doi: 10.1038/pr.2017.179

117. Berrington JE, Clarke P, Embleton ND, Ewer AK, Geethanath R, Gupta S, et al. Retinopathy of prematurity screening at $\geq 30$ weeks: urinary NTproBNP performance. Acta Paediatr. (2018) 107:1722-5. doi: 10.1111/apa.14354

118. Markasz L, Olsson KW, Holmström G, Sindelar R. Cluster analysis of early postnatal biochemical markers may predict development of retinopathy of prematurity. Transl Vis Sci Technol. (2020) 9:14. doi: 10.1167/tvst.9.13.14

119. Gohari M, Dastgheib SA, Noorishadkam M, Lookzadeh MH, Mirjalili SR, Akbarian-Bafghi MJ, et al. Association of eNOS and ACE polymorphisms with retinopathy of prematurity: a systematic review and meta-analysis. Fetal Pediatr Pathol. (2020) 39:334-45. doi: 10.1080/15513815.2019.1652378

120. Matsumoto T, Saito Y, Itokawa T, Shiba T, Oba MS, Takahashi H, et al. Retinal VEGF levels correlate with ocular circulation measured by a laser specklemicro system in an oxygen-induced retinopathy rat model. Graefes Arch Clin Exp Ophthalmol. (2017) 255:1981-90. doi: 10.1007/s00417-017-3756-0

121. Becker PS, Suck G, Nowakowska P, Ullrich E, Seifried E, Bader P, et al. Selection and expansion of natural killer cells for NK cellbased immunotherapy. Cancer Immunol Immunother. (2016) 65:47784. doi: 10.1007/s00262-016-1792-y 
122. Chanput W, Mes JJ, Wichers HJ. THP-1 cell line: an in vitro cell model for immune modulation approach. Int Immunopharmacol. (2014) 23:3745. doi: 10.1016/j.intimp.2014.08.002

123. Beer L, Mildner M, Gyöngyösi M, Ankersmit HJ. Peripheral blood mononuclear cell secretome for tissue repair. Apoptosis. (2016) 21:133653. doi: 10.1007/s10495-016-1292-8

124. Xiao D, Ling KHJ, Custodio J, Majeed SR, Tarnowski T. Quantitation of intracellular triphosphate metabolites of antiretroviral agents in peripheral blood mononuclear cells (PBMCs) and corresponding cell count determinations: review of current methods and challenges. Expert Opin Drug Metab Toxicol. (2018) 14:781-802. doi: 10.1080/17425255.2018.1500552

125. Bagci S, Mueller A, Reinsberg J, Heep A, Bartmann P, Franz AR. Saliva as a valid alternative in monitoring melatonin concentrations in newborn infants. Early Hum Dev. (2009) 85:595-8. doi: 10.1016/j.earlhumdev.2009.06.003

126. Khamis MM, Adamko DJ, El-Aneed A. Mass spectrometric based approaches in urine metabolomics and biomarker discovery. Mass Spectrom Rev. (2017) 36:115-34. doi: 10.1002/mas.21455

127. Hartnett ME, Penn JS. Mechanisms and management of retinopathy of prematurity. N Engl J Med. (2012) 367:251526. doi: 10.1056/NEJMra1208129

128. Reich ES. Pre-term births on the rise. Nature. (2012) 485:20. doi: 10.1038/485020a

129. Brown JM, Campbell JP, Beers A, Chang K, Ostmo S, Chan RVP, et al. Automated diagnosis of plus disease in retinopathy of prematurity using deep convolutional neural networks. JAMA Ophthalmol. (2018) 136:80310. doi: 10.1001/jamaophthalmol.2018.1934

130. Kaštelan S, Orešković I, Bišćan F, Kaštelan H, Gverović Antunica A. Inflammatory and angiogenic biomarkers in diabetic retinopathy. Biochem Med (Zagreb). (2020) 30:030502. doi: 10.11613/BM.2020.030502
131. Hosokawa K. Biomarker analysis on a power-free microfluidic chip driven by degassed poly(dimethylsiloxane). Anal Sci. (2021) 37:399406. doi: 10.2116/analsci.20SCR04

132. Sobsey CA, Ibrahim S, Richard VR, Gaspar V, Mitsa G, Lacasse V, et al. Targeted and untargeted proteomics approaches in biomarker development. Proteomics. (2020) 20:e1900029. doi: 10.1002/pmic.2019 00029

133. Gohil SH, Iorgulescu JB, Braun DA, Keskin DB, Livak KJ. Applying high-dimensional single-cell technologies to the analysis of cancer immunotherapy. Nat Rev Clin Oncol. (2021) 18:244-56. doi: 10.1038/s41571-020-00449-x

Conflict of Interest: The authors declare that the research was conducted in the absence of any commercial or financial relationships that could be construed as a potential conflict of interest.

Publisher's Note: All claims expressed in this article are solely those of the authors and do not necessarily represent those of their affiliated organizations, or those of the publisher, the editors and the reviewers. Any product that may be evaluated in this article, or claim that may be made by its manufacturer, is not guaranteed or endorsed by the publisher.

Copyright (C) 2022 Tan, Li, Wang, Zou, Jia, Yoshida and Zhou. This is an open-access article distributed under the terms of the Creative Commons Attribution License (CC $B Y)$. The use, distribution or reproduction in other forums is permitted, provided the original author(s) and the copyright owner(s) are credited and that the original publication in this journal is cited, in accordance with accepted academic practice. No use, distribution or reproduction is permitted which does not comply with these terms. 